\title{
Estudo cladístico e descrições de tribos em Pyrrhopyginae (Lepidoptera, Hesperiidae)
}

\author{
Olaf H.H. Mielke ${ }^{1}$
}

\begin{abstract}
Cladistic study and descriptions of tribes in Pyrrhopyginae (Lepidoptera, Hesperiidae). A cladistic study of the four monophyletic tribes of Pyrrhopyginae is presented. Passovini, Oxynetrini, and Zoniini are new tribes.

KEY WORDS. Lepidoptera, Hesperiidae, Pyrrhopyginae, new tribes, cladistic
\end{abstract}

Ao iniciar um estudo sistemático dos Pyrrhopyginae Mabille, 1877, cujas espécies ocorrem na região neotropical até o norte da Argentina e Bolívia e com apenas uma penetrando no sul dos Estados Unidos da América do Norte, deparou-se com uma série de problemas na sistemática superior. Poucos foram os autores que estudaram a subfamília de forma completa (WATSON 1893; GODMAN \& SALVIN 1893; Mabille 1903; MaBille \& Boullet 1908; Bell 1931, 1933, 1934a,b; EvANS 1951). Destes, somente EvANS (1951) estabeleceu agrupamentos, por ele chamados de seções, para os 20 gêneros até então estabelecidos.

No trabalho de DE JONG et al. (1996), onde há um análise cladística das subfamílias de Hesperioidea, juntamente com as demais famílias e subfamílias de Papilionoidea, é evidenciada a monofilia dos Pyrrhopyginae, como grupo irmão de Urbanus Hübner, [1807] (Pyrginae: Eudamini) e das demais subfamílias (representadas por alguns outros gêneros: Bibasis Moore, 1881 -Coeliadinae, Euschemon Doubleday, 1847 - Pyrginae, Celaenorrhinus Hübner, [1819] - Pyrginae, Trapezites Hübner, 1823 - Trapezitinae, Heteropterus Duméril, 1806 - Eumesiinae, Hesperia Fabricius, 1793, Pyrgus Hübner, [1819] - Pyrginae, Megathymus Scudder, 1872 - Megathyminae); no entanto, este autor não levou em consideração os caracteres tradicionalmente conhecidos para a divisão da família em subfamílias. ACKERY et al. (1999) confirmam as hipóteses de parentesco filogenético relacionadas por DE JONG et al. (1996), caracterizando a subfamília (1) pelo formato da antena em que toda a clava terminal está após a curvatura, e (2) pelo primeiro tergo abdominal comprimido entre o tórax e o segundo tergo abdominal, mais ou menos em forma de escama. Como Pyrrhopyginae só ocorre no Novo Mundo, acredita-se que tenha evoluído após a separação das Américas. Pyrginae, o grupo irmão, e os Hesperiinae são cosmopolitas, enquanto que as demais subfamílias apresentam distribuições geográficas mais restritas: Coeliadinae ocorre nos trópicos do Velho Mundo; Trapezitinae na Austrália e ao norte, através da Nova Guiné, até as Molucas; Megathyminae nas Américas do Norte e Central; e Eumesiinae (= Cyclopidinae, Heteropterinae) ausente apenaz na região oriental e Austrália.

1) Contribuição número 1185 do Departamento de Zoologia, Universidade Federal do Paraná.

2) Departamento de Zoologia, Universidade Federal do Paraná. Caixa Postal 19020 81531-990 Curitiba, Paraná, Brasil. Bolsista do CNPq. 
O estudo da revisão sistemática dos Pyrrhopyginae visa reconceituar os gêneros e descrever os novos, os quais serão apresentados em artigos futuros, e apresentar uma proposta para as relações filogenéticas com a definição das tribos.

A presente análise filogenética suporta a existência de quatro grupos monofiléticos iniciais, aqui consideradas tribos: Pyrrhopygini, Oxynetrini, Zoniini e Passovini, sendo as três últimas descritas como novas.

\section{MATERIAL E MÉTODOS}

Para a análise taxonômica total da subfamília, foram analisados 89 caracteres de 133 espécies das 157 atualmente conhecidas. Nenhuma espécie, a priori, julgada muito diferente, foi ignorada. A análise restrita da espécie tipo de cada gênero certamente não ofereceria resultados coerentes, pois, na maioria das vezes, esta não é a que possui os caracteres diagnósticos para cada um dos gêneros, além da dificuldade em saber quais os caracteres e estados apomórficos para cada um dos gêneros. Também seria impossível estabelecer novos gêneros, pois só se trabalharia com gêneros conhecidos. O resultado da análise dos gêneros, a ser publicado posteriormente, corrobora este pensamento, mostrando que alguns deverão ser descritos para incluir aquelas espécies com caracteres conflitantes em relação aos gêneros estabelecidos.

No levantamento dos caracteres foram consideradas todas as estruturas julgadas importantes pelos autores mencionados na introdução, acrescidos de novos caracteres. Todos referem-se à morfologia da cabeça, incluindo antenas e palpos, do tórax, incluindo pernas, venações e aspectos alares, e do abdome, incluindo genitálias masculina e feminina, e à aspectos cromáticos.

$\mathrm{Na}$ análise das tribos, aqui apresentada, foram utilizados 18 caracteres, dos 89 estudados, que definiram quatro grandes grupos (Tab I). Os caracteres são binários e multiestados, sendo polarizados pelo método de comparação com um grupo externo hipotético (DE JoNG et al. 1996). Seria difícil realizar um levantamento dos estados dos caracteres utilizados em número razoável de espécies de Pyrginae, sendo os estados do grupo externo considerados no estado " 0 ". Os caracteres foram codificados como 0 (plesiomórfico) e 1, 2 e 3 (apomórficos); caracteres em multiestados foram considerados inicialmente não ordenados e posteriormente ordenados.

Para a análise utilizou-se o programa Hennig86, com a opção "ie*" (FARRIS 1988).

Tab. I. Matriz de dados utilizada na análise cladistica de Pyrrhopyginae.

\begin{tabular}{lllllllllllllllllll}
\hline & 1 & 2 & 3 & 4 & 5 & 6 & 7 & 8 & 9 & 0 & 1 & 2 & 3 & 4 & 5 & 6 & 7 & 8 \\
\hline Grupo externo & 0 & 0 & 0 & 0 & 0 & 0 & 0 & 0 & 0 & 0 & 0 & 0 & 0 & 0 & 0 & 0 & 0 & 0 \\
Passovini & 0 & 0 & 0 & 0 & 0 & 0 & 0 & 0 & 1 & 0 & 0 & 0 & 1 & 1 & 0 & 0 & 1 & 1 \\
Oxynetrini & 1 & 0 & 0 & 0 & 0 & 0 & 1 & 2 & 0 & 1 & 2 & 2 & 0 & 0 & 2 & 0 & 1 & 1 \\
Zoniini & 0 & 1 & 1 & 1 & 1 & 1 & 0 & 1 & 0 & 0 & 1 & 1 & 0 & 0 & 1 & 1 & 1 & 1 \\
Pyrrhopygini & 0 & 0 & 0 & 0 & 0 & 0 & 0 & 0 & 0 & 0 & 2 & 3 & 0 & 0 & 3 & 0 & 1 & 1 \\
\hline
\end{tabular}




\section{Caracteres utilizados na análise cladística das tribos}

Caráter 1. $\mathrm{Na}$ asa anterior, as veias discocelulares mediana $(\mathrm{dcm})$ e inferior (dci) aproximadamente paralelas à margem externa e dirigidas para o centro da margem interna (0); ou não paralelas e dirigidas ao torno (1).

Quando as veias discocelulares são aproximadamente paralelas à margem externa, uma reta imaginária que passa pela base das veias M1 e M3 e atingindo a veia $2 \mathrm{~A}$, forma com esta um ângulo externo menor que $851(0)$; e quando não paralelas, o ângulo é maior que 851 (1).

O estado (0) é o plesiomórfico, enquanto que o estado (1) é sinapomórfico para Oxynetrini (Figs 1-2).

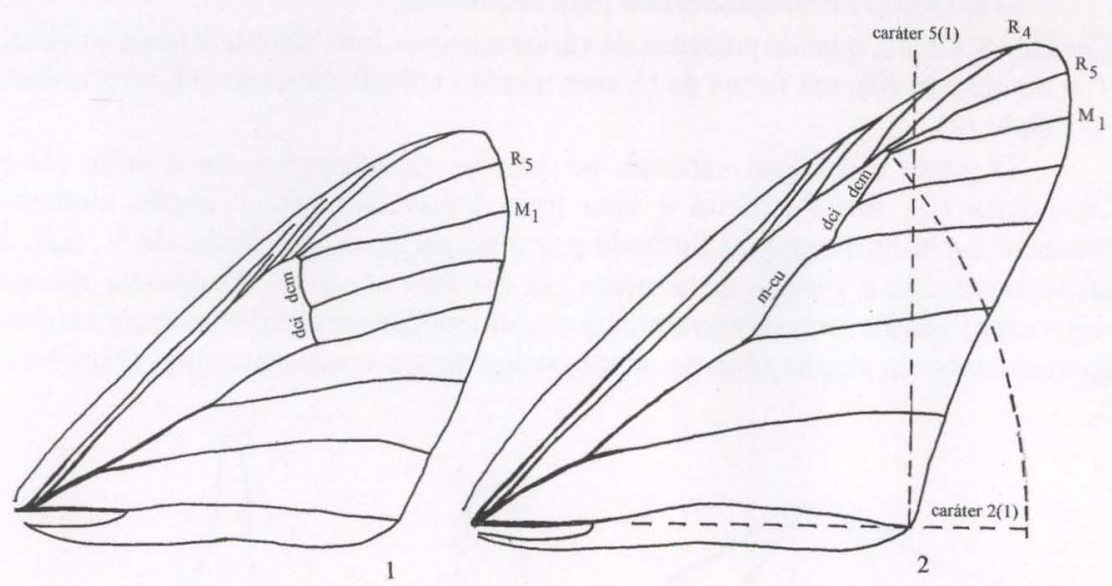

Figs 1-2. (1) Asa anterior, venação: Oxynetra confusa, caráter 1(1) -discocelulares dirigidas para o torno; (2) venaçăo da asa anterior de Zonia zonia zonia, caracteres $1(0), 2(1), 3(1)$, $4(1), 5(1)$

Caráter 2. $\mathrm{Na}$ asa anterior, o comprimento da célula discal menor que o comprimento da veia $2 \mathrm{~A}$ mais as discocelulares mediana (dem) e inferior (dci) (0); ou maior (1).

O estado (1) é apomórfico para Zoniini (Fig. 1).

Caráter 3. Na asa anterior, as veias R5 e M1 uniformemente divergentes desde a base até a margem externa (0); ou aproximadas no quarto basal e depois abruptamente divergentes por curtra distância e daí suavemente até a margem externa (1).

O estado (1) é apomórfico para Zoniini (Fig 2).

Caráter 4. Na asa anterior, ângulo externo entre a veia discocelular inferior (dci) e a médio-cubital (m-cu) maior que 251 (0); ou menor que 101 (1).

O estado (1) é apomórfico para Zoniini (Fig. 2).

Caráter 5. Asa anterior do macho pouco projetada (0), ou muito projetada (1).

Uma reta perpendicular à veia $2 \mathrm{~A}$, a partir do encontro desta com a margem 
externa, passa pelas proximidades da veia R4; com a distância desta perpendicular ao término da veia R4 menor que as discocelulares mediana $(\mathrm{dcm})$ e inferior (dci) (0); ou maior (1).

O estado (1) é apomórfico para Zoniini (Fig. 2).

Caráter 6. Perna metatorácica com o fêmur longo, ou seja, este rebatido sobre a tíbia ultrapassando o meio entre os dois pares de esporões (0); ou curto, não ultrapassando o meio entre os esporões (1).

O estado (1) é apomórfico para Zoniini.

Caráter 7. Projeção anterior do saco mais longa que larga (0); ou mais larga que longa (1).

O estado (1) é sinapomórfico para Oxynetrini.

Caráter 8. Gnato, quando presente, de vários aspectos, mas não como nos seguintes, ou ausente $(0)$; em forma de $\mathrm{U}$, com a união voltada para trás (1); ou arredondado (2).

O gnato é bastante variável, no entanto, característico em Zoniini (1) e Oxynetrini (2). Em Passovini é uma barra transversal com projeção mediana posterior e em Pyrrhopygini formado por duas peças, ou em forma de $\mathrm{V}$, com a união espessada e voltada distalmente [só em uma espécie - Nosphistia zonara (Hewitson, 1866)], mas provavelmente evoluiu independendentemente para o desaparecimento em alguns gêneros, sendo então ausente nestas duas tribos (Figs 3-7).
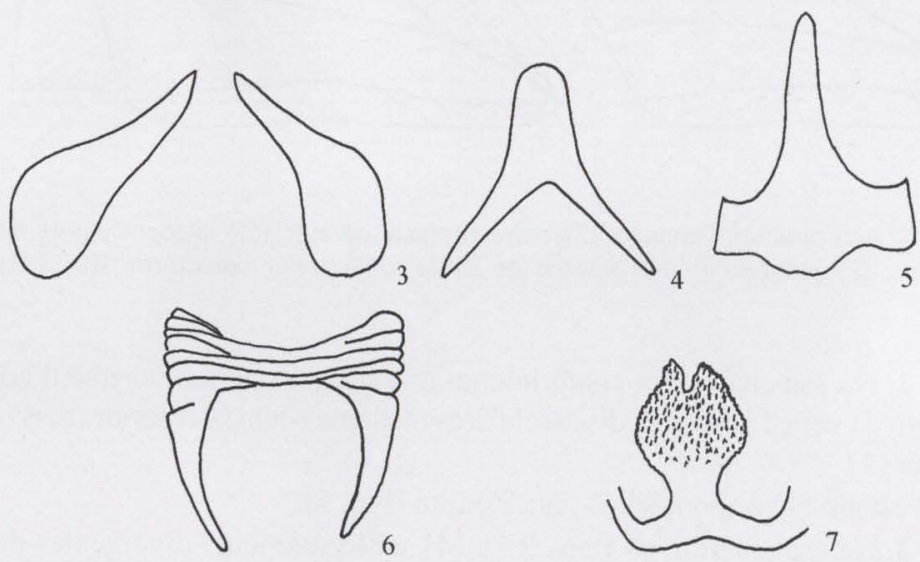

Figs 3-7. Gnatos, vistas ventrais. (3) Pyrrhopyge charybdis charybdis, caráter $8(0)$; (4) Nosphistia zonara, caráter $8(0)$; (5) Azonax typhaon, caráter $8(0)$; (6) Zonia zonia zonia, caráter $8(1) ;(7)$ Oxynetra roscius roscius, caráter $8(2)$.

Caráter 9. Edeago curto, menor que o comprimento da valva (0); ou longo, maior que o comprimento da valva (1).

O estado (1) é sinapomórfico para Passovini (1). O edeago em Zoniini é um tubo curto e simples, enquanto que em Pyrrhopygini pode ser desta forma ou com 
outros aspectos, praticamente caracterizando cada um dos seus gêneros.

Caráter 10. Edeago com o terço distal não curvado ventralmente $(0)$; ou com o terço distal curvado ventralmente (1).

O estado (1) é sinapomórfico para Oxynetrini.

Caráter 11. Vesica do edeago com no mínimo um cornuto espiniforme igual ou maior que a largura da abertura distal do edeago, ou se menor, com uma área de pontos esclerotinizados $(0)$; ou com três cornutos grandes, maiores que a abertura distal do edeago e compostos cada um de pequenos espinhos (1); ou sem cornuto, ou quando presente diminuto e menor que abertura distal do edeago (2).

A presença de cornuto é considerado plesiomórfico em Lepidoptera, no entanto, quando presente o seu aspecto é muito variável. Com essa plesiomorfia está Myscelus amystis (Hewitson, 1867), única espécie do grupo com um cornuto menor que a abertura distal do edeago e uma área de pontos esclerotinizados na vesica, mas que por todos os outros caracteres pertence a este gênero. O estado (0) caracteriza os Passovini, (1) Zoniini e (2) Pyrrhopygini e Oxynetrini, sendo sempre ausente nesta.

Caráter 12. Juxta pequena, menor que três vezes o diâmetro do edeago e voltada distalmente, onde suporta o edeago (0); ou pequena e em forma de $\mathrm{V}$ e afastada do edeago (1); ou pequena e em forma de um cone com a base aberta para o lado distal (2); ou grande, maior que cinco vezes o diâmetro do edeago, ou em forma de um anel fino contornando do edeago (3).

O estado apmórfico (3) foi observado em um grupo de espécies de um novo gênero, próximo de Mimoniades Hübner, 1825 e Ardaris Watson, 1893, no qual a juxta se modificou para formar um anel que contorna o edeago; estas espécies pertencem por todos os outros caracteres a Pyrrhopygini. O estado (0) caracteriza os Passovini, (1) Zoniini, (2) Oxynetrini e (3) Pyrrhopygini.

Caráter 13. Valva alongada e com a parte dorsal (ampula) igual ou maior que dois terços do comprimento da parte ventral (harpe), formando um lóbulo separado (0); ou com a parte do ${ }^{\cdots}$ רl da valva não atingindo os dois terços da parte ventral, ou se atinge, não forma lóvilo separado e o aspecto é alargado (1).

O estado (1) é si: : omórfico para Passovini.

Caráter 14. Esterigma não em forma de lâmina e bífida na ponta distal $(0)$; ou em lâmina bífida (1). O estado (1) é sinapomórfico para Passovini. Na demais tribos é muito variável, caracterizando os gêneros.

Caráter 15. Lamela pós-vaginal aproximadamente triangular (0); ou alargada transversalmente, com projeção rombóide na parte mediaıa anterior e com pequena concavidade na parte mediana posterior (1); ou aproximadamente retangular, com os cantos posteriores arredondados e os anteiiores côncavos (2); ou membranosa, ou representada por pouca esclerotinização no diafragma, ou representada por dobra membranosa espessada - uma espécie: Mysoria thasus (Stoll, 1781), ou aproximadamente retangular, com os ângulos proximais externos expandidos e com concavidade na parte mediana posterior-uma espécie: Pyrrhopyge aerata (Godman \& Salvin, 1879) (3). 
A presença da lamela pós-vaginal é considerada uma plesiomorfia, enquanto que a sua ausência apomórfico. Muito variável na subfamília e bom caracterer para dignosticar os gêneros. O estado (0) caracteriza Passovini, (1) Zoniini, (2) Oxynetrini e (3) Pyrrhopygini.

Caráter 16. Bolsa copuladora sem (0); ou com signos (1).

O estado (1) é apomórfico para Zoniini

\section{Caracteres autapomórficos de pyrrhopyginae}

Caráter 17. Antena com a clava não após a curvatura (0); ou após a curvatura (1).

Caráter 18. Primeiro tergo abdominal não comprimido entre o tórax e o abdome (0); ou comprimido, mais ou menos em forma de escama (1).

\section{RESULTADOS E CONCLUSÕES}

A análise cladística entre os taxa com o programa Hennig86, comando "ie* (FARRIS 1988), e os caracteres não ordenados resultou em quatro cladogramas todos com os índices de consistência 100 e de retenção 100 , sendo o comprimento de 22 passos, enquanto que com os caracteres ordenados resultou em um só cladograma com os índices de consistência 96 e o de retenção 85, sendo o comprimento de 23 passos. O cladograma de consenso com os caracteres não ordenados resultou em simples politomia, óbviamente um resultado não informativo.

Um dos cladogramas resultantes com os caracteres não ordenados foi igual ao cladograma com os caracteres ordenados e julgado como o mais informativo sobre a filogenia dos Pyrrhopyginae.

Os caracteres 1 a 16 indicaram os seguintes agrupamentos e tribos, todos monofiléticos, sendo que os caracteres 17 e 18 sugerem a monofilia dos Pyrrhopyginae (Fig. 8). O cladograma forma inicialmente dois clados monofiléticos, o primeiro formado pelas sinapomorfias $9(1)$ - edeago maior que o comprimento da valva, 13(1) - valva alongada e com a parte dorsal (ampula) igual ou maior que dois terços do comprimento da parte ventral (harpe), formando um lóbulo separado e 14(1) - e esterigma em lámina bífida, que caracterizaram os Passovini, e o segundo com as sinapomorfias 8(1) -gnato em forma de U (não em Oxynetrini e Pyrrhopygini), 11(1) - vesica do edeago com três cornutos grandes compostos cada um de pesquenos espinhos (não em Oxynetrini e Pyrrhopygin), 12(1) - juxta pequena, em forma de V e afastada do edeago (não em Oxynetrini e Pyrrhopygini) e 15(1) lamela pós-vaginal alargada transversalmente, com projeção romboide na parte mediana anterior e com pequena concavidade na parte mediana posterior, que formaram o grupo Zoniini+Oxynetrini+Pyrrhopygini. Este grupo é formado por outros dois clados, o primeiro separou os Zoniini pelas apomorfias 2(1) - na asa anterior, o comprimento da célula discal maior que a soma da veia $2 \mathrm{~A}$ e as discocelulares mediana e inferior, 3(1) - na asa anterior, as veias R5 e M1 aproximadas no quarto basal e depois abruptamente divergentes por curta distância e dai suavemente até a margem externa, 4(1) - na asa anterior, o ângulo entre a veia $\mathrm{m}$-cu e a veia discocelular inferior menor que 101, 5(1) - Asa anterior do macho muito projetada, $6(1)$ - perna metatorácica com o fêmur curto, isto é, quando rebatido sobre a tíbia não ultrapassando o meio entre os esporões e 16(1) - bolsa 


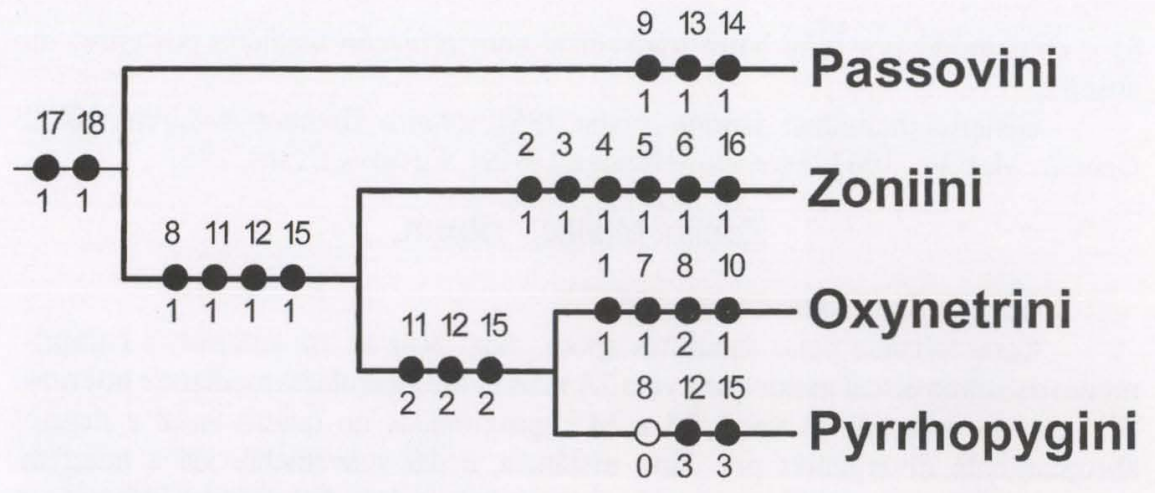

Fig. 8. Cladograma com as relações filogenéticas das tribos de Pyrrhopyginae, mostrando a distribuição dos caracteres. Círculos negros $=$ apomorfias, círculo branco $=$ reversão .

copuladora com signos. O segundo formado pelas sinapomorfias 11(2) - vesica do edeago com um cornuto diminuto, menor que a abertura do edeago, ou sem cornuto, 12(2) - juxta pequena e em forma de um cone com a base aberta para o lado externo (posterior) (não em Pyrrhopyginae) e 15(2) - lamela pós-vaginal aproximadamente retangular, com os cantos posteriores arredondados e os anteriores côcavos (não em Pyrrhopyginae) constituiram o grupo Oxynetrini+Pyrrhopygini, aquele definido pelas sinapomorfias $1(1)$ - na asa anterior, as veias discocelulares não paralelas à margem externa, dirigidas para o torno, $7(1)$ - projeção anterior do saco mais larga que longa, $8(2)$ - gnato arredondado e 10(1) - edeago com o terço distal curvado ventralmente, e este pelas sinapomorfias 12(3) - juxta grande, maior que três vezes o diâmetro do edeago, ou em forma de um anel fino em volta do edeago e 15(3) lamela pós-vaginal aproximadamente retangular, com os ângulos proximais externos expandidos e com concavidade na parte mediana posterior, e afastado do esterigma e do oitavo esterno por uma distância igual à metade de sua largura, ou representada por pequena esclerotinização no diafragma ou membranosa, e pela plesiomorfia 8(0) - gnato não em forma de $\mathrm{U}$ ou arredondado.

Desta forma, Pyrrhopyginae apresenta quatro tribos monofiléticas, a seguir caracterizadas. Os gêneros nelas contidos são mencionados a seguir.

\section{Passovini Mielke, tribo $\mathrm{n}$.}

Gênero-tipo: Passova Evans, 1951

Caracterizada pelas seguintes sinapomorfias: $9(1)$ - edeago longo, ou seja, maior que o comprimento da valva 13(1) - valva alongada e com a parte dorsal (ampula) igual ou maior que dois terços do comprimento da parte ventral (harpe), formando um lóbulo separado e 14(1) - esterigma em forma de lâmina com a ponta distal bífida; e pelas seguintes plesiomorfias: 11(0) -vesica com no mínimo um cornuto espiniforme igual ou maior que a largura da abertura distal do edeago, ou se menor, então com uma área de pontos escelerotinizados, $12(0)$ - juxta pequena, menor que três vezes o diâmetro do edeago e dobrada para trás, onde repouso o edeago, 15(0) - lamela pós-vaginal aproximadamente triangular. O gnato (caráter 
8) é constituido por uma barra transversal com projeção mediana posterior, ou ausente.

Gêneros incluídos: Aspitha Evans, 1951; Azonax Godman \& Salvin, 1893; Granila Mabille, 1903; Myscelus Hübner, [1819]; Passova Evans, 1951.

\section{Zoniini Mielke, ribo $\mathrm{n}$.}

Gênero-tipo: Zonia Evans, 1951.

Caracterizada pelas seguintes apom. fias: $2(1)$ na asa anterior, o comprimento da celula discal maior que a veia $2 \mathrm{~A}$ mais as discocelulares mediana e inferior; 3(1) na asa anterior, as veias R5 e M1 aproximadas no quarto basal e depois abruptamente divergentes por curta distância, e dai suavemente até a margem externa; 4(1) na asa anterior, o ângulo externo entre a veia discocelular inferior e a média-cubital menor que $101 ; 5(1)$ asa anterior do macho muito projetada; $6(1)$ perna metatorácica com o fêmur curto, ou seja, rebatido sobre a tíbia não ultrapassa o meio entre os dois pares de esporões; 8(1) gnato de uma só peça, bem esclerotinizado, em forma de $U$, com a união voltada para trás; 11(1) vesica do edeago com três cornutos compostos cada um de pequenos espinhos; 12(1) juxta pequena, menor que três vezes o diâmetro do edeago, em forma de $\mathrm{V}$ e afastada do edeago; 15(1) lamela pós-vaginal alargada transversalmente e com uma projeção rombuda na parte mediana anterior, e com pequena concavidade na parte mediana posterior; 16(1) bolsa copuladora com signos.

Gênero incluído: Zonia Evans, 1951.

\section{Oxynetrini Mielke, tribo $\mathrm{n}$.}

Gênero-tipo: Oxynetra C. Felder \& R. Felder, 1862

Caracterizada pelas seguintes sinapomorfias: 31(1) na asa anterior, as discocelulares dirigidas para a proximidade do torno; $7(1)$ projeção anterior mais larga que longa; 8(2) gnato arredondado; 10(1) edeago com o terço distal curvado ventralmente; 11(3) vesica do edeago sem cornuto; 12(2) juxta pequena, menor que três vezes o diâmetro do edeago, em forma de cone com a base aberta para o lado distal; 15(2) lamela pós-vaginal aproximadamente retangular, com os cantos posteriores arredondados e os anteriores côncavos.

Gênero incluído: Oxynetra C. Felder \& R. Felder, 1862.

\section{Pyrrhopygini Mabille, 1877}

Gênero-tipo: Pyrrhopyge Hübner, [1819]

Caracterizada pelas seguintes sinapomorfias: 11(2) vesica do edeago sem cornuto, ou quando presente, diminuto e menor que a abertura do edeago (ausente também em Oxynetrini); 12(3) juxta grande, maior que cinco vêzes o diâmetro do edeago, ou em forma de anel fino contornando o edeago; 15(3) lamela pós-vaginal membranosa, ou representada por fraca esclerotinização no diafragma, ou representada por dobra membranosa espessada - só uma espécie: Mysoria thasus (Stoll, 1781), ou aproximadamente retangular, com os ângulos proximais externos expandidos e com concavidade na parte mediana posterior - só uma espécie: Pyrrhopyge 
aerata (Godman \& Salvin, 1879) (3). O gnato (caráter 8) é normalmente constituido de duas peças separadas, ou em forma de $\mathrm{V}$ com a união prolongada para trás - só em uma espécie: Nosphistia zonara), ou ausente.

Gêneros incluídos: Amenis Watson, 1893; Ardaris Watson, 1893; Croniades Mabille, 1903; Elbella Evans, 1951; Jemadia Watson, 1893; Metardaris Mabille, 1903; Microceris Watson, 1893; Mimoniades Hübner, 1823; Mysoria Watson, 1893; Nosphistia Mabille \& Boullet, 1908; Parelbella Mielke, 1995; Protelbella Mielke, 1995; Pseudocroniades Mielke, 1995; Pyrrhopyge Hubner, [1819]; Sarbia Watson, 1893.

Estas tribos, em parte, coincidem com as quatro seções estabelecidas por Evans (1951) para a subfamília, ou sejam, as seções Pyrrhopyge e Mimoniades formam os Pyrrhopygini, a seção Myscelus a tribo Passovini e a seção Oxynetra a tribo Oxynetrini. A seção Mimoniades apresentou-se, numa análise preliminar, como um agrupamento parafilético dentro de Pyrrhopygini.

AGRADECIMENTOS. Aos colegas Drs. Mirna Martins Casagrande, Sionei Ricardo Bonatto e Marcelo Duarte pela leitura crítica do manuscrito com valiosas sugestões, sem as quais este artigo não teria chegado ao fim.

\section{REFERÊNCIAS BIBLIOGRÁFICAS}

Ackery, P.R.; R. DE Jong \& R.I. VANe-Wright. 1999. The butterflies: Hydeloidea, Hesperioidea and Papilionoidea, p. 263-300. In: P.N. KRISTENSEN. (Ed.). Band/Volume IV Arthropoda: Insecta. Lepidoptera, moths and butterflies: evolution, systematics, and biogeography. Vol. 1, X+491p. In: M. Fischer (Ed.). Handbuch der Zoologie. Handbook of Zoology. Berlin, New York, Walter de Gruyter.

BELL, E.L. 1931. Studies in the Pyrrhopyginae, with descriptions of several new species (Lepidoptera, Rhopalocera, Hesperiidae). Jour. N.Y. Ent. Soc. 39: 417-490.

- 1933. Studies in the Pyrrhopyginae, with descriptions of new species. Jour. N.Y. Ent. Soc. 41: 265-295.

- 1934a. Studies in the Pyrrhopyginae, with descriptions of new species (Lepidoptera, Rhopalocera, Hesperiidae). Jour. N.Y. Ent. Soc. 41 (1933): 481-529.

-1934b. Studies in the Pyrrhopyginae (Lepidoptera, Rhopalocera, Hesperiidae). Jour. N.Y.

Ent. Soc. 42: 393-440.

DE JONG, R.; R.I. VANE-WRIGHT \& P.R. ACKERY. 1996. The higher classification of butterflies (Lepidoptera): problems and prospects. Ent. scand. 27: 65-101.

Evans, W.H. 1951. A catalogue of the American Hesperiidae indicating the classification and nomenclature adopted in the British Museum (Natural History). Part I. Introduction and Group A Pyrrhopyginae. London, British Museum (Natural History), X+92p.

FARRIS, J.S. 1988. Hennig86. Version 1.5. New York, Port Jefferson Station, Edição do autor.

GodmAn, F.D. \& O. SALvin. 1887-1901. Biologia Centrali-Americana. Insecta. Lepidoptera-Rhopalocera 2. London, Dulau \& Co., Bernard Quaritch, 782p.

Mabille, P. 1903-1904. Lepidoptera Rhopalocera. Fam. Hesperidae. In. P. WytSman. Genera Insectorum 17a. Bruxelles, V. Verteneuil \& L. Desmet, 219p.

Mabille, P. \& E. Boullet. 1908. Essai de révision de la fàmille des hespérides. Ann. Sc. nat., Zool., Paris, (9) 7: 167-207.

WAtson, E.Y. 1893. A proposed classification of the Hesperiidae, with a revision of the genera. Proc. zool. Soc. London 1893: 3-132.

Recebido em 15.XII.2000; aceito em 23.VIII.2001. 